This item was submitted to Loughborough's Research Repository by the author.

Items in Figshare are protected by copyright, with all rights reserved, unless otherwise indicated.

\title{
Optically reconfigurable microstrip UWB bandpass filters
}

PLEASE CITE THE PUBLISHED VERSION

http://www.lapconf.co.uk/lapc2010.php

\section{PUBLISHER}

Loughborough University (@ IEEE)

\section{VERSION}

VoR (Version of Record)

\section{LICENCE}

CC BY-NC-ND 4.0

\section{REPOSITORY RECORD}

Athukorala, L., K. Rabbi, C.J. Panagamuwa, J.C. Vardaxoglou, M. Philippakis, and D. Budimir. 2019. "Optically Reconfigurable Microstrip UWB Bandpass Filters". figshare. https://hdl.handle.net/2134/8085. 
This item was submitted to Loughborough's Institutional Repository (https://dspace.lboro.ac.uk/) by the author and is made available under the following Creative Commons Licence conditions.

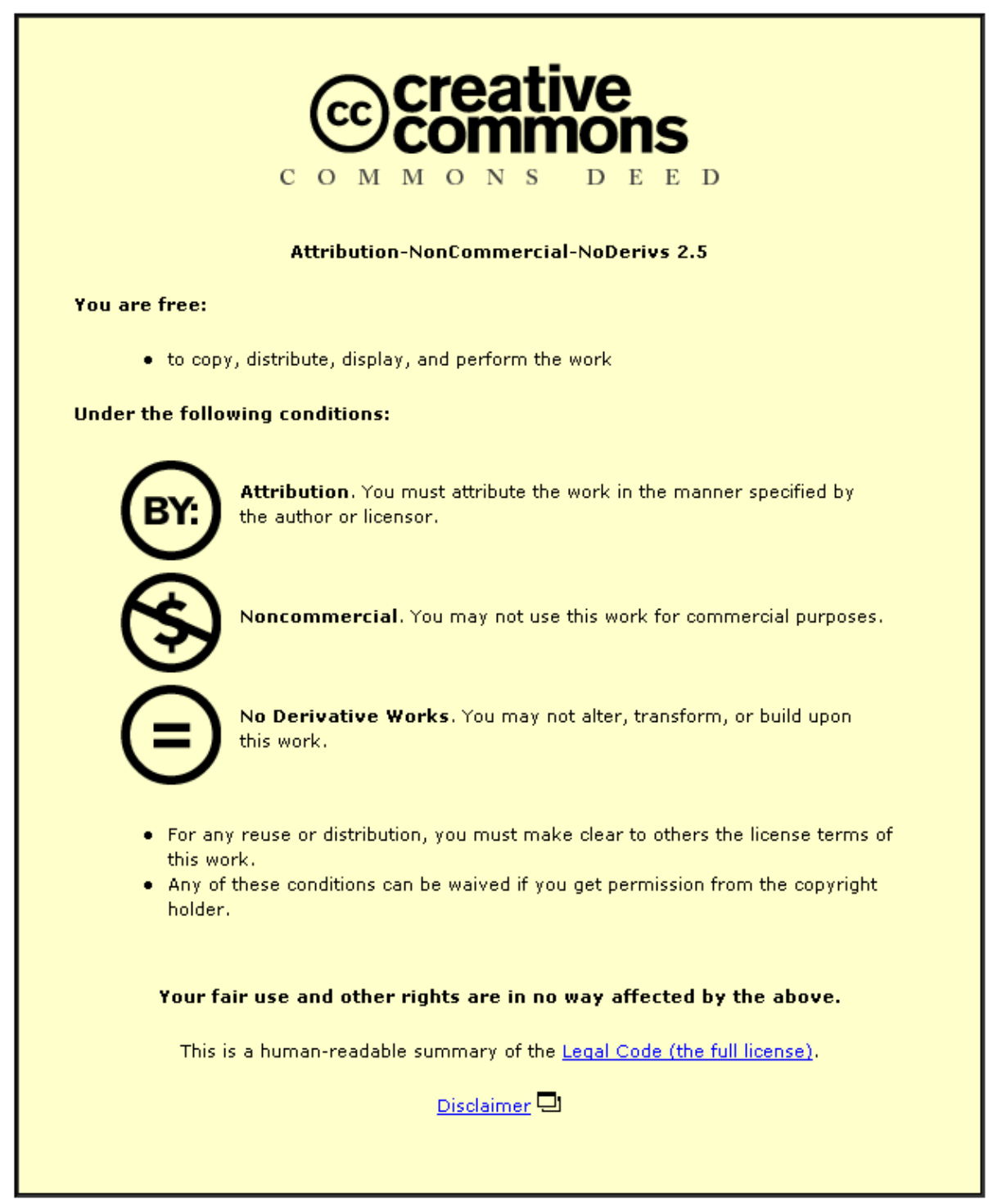

For the full text of this licence, please go to: http://creativecommons.org/licenses/by-nc-nd/2.5/ 


\title{
Optically Reconfigurable Microstrip UWB Bandpass Filters
}

\author{
L. Athukorala ${ }^{\# 1}$, K. Rabbi ${ }^{\# 2}$, C. Panagamuwa ${ }^{* 3}$, J.C. Vardaxoglou ${ }^{* 4}$, M. Philippakis ${ }^{+5}$, D. Budimir ${ }^{\# 6}$ \\ ${ }^{*}$ Wireless Communications Research Group, School of Electronics and Computer Science, \\ University of Westminster, 115 New Cavendish Street, London, W1W 6UW, UK \\ d.budimir@westminster.ac.uk \\ ${ }^{*}$ Wireless Communications Research Group, Loughborough University, Loughborough, UK \\ ${ }^{3}$ c.j.panagamuwa@lboro.ac.uk \\ ${ }^{+}$Cobham Technical Services, Cleve Road, Leatherhead, Surrey, KT22 7AS, UK
}

\begin{abstract}
This paper presents an optically reconfigurable microstrip ultra-wideband filter. A single optical switch comprised of a silicon wafer is activated using near infra-red light to select between either a bandpass or bandstop response. With the switch in the $O N$ state, the circuit behaves as a bandpass filter while in the OFF state, the circuit behaves as a bandstop filter in the same frequency band. The proposed filter was designed, fabricated and tested. Its performance was evaluated through simulation and measurements.
\end{abstract}

\section{INTRODUCTION}

Ultra wideband (UWB) filters have seen a sharp rise in demand recently due to the commercialisation of the $3.1 \mathrm{GHz}$ $-10.6 \mathrm{GHz}$ band. This band however is divided into a lower and upper band of $3.1 \mathrm{GHz}-5 \mathrm{GHz}$ and $6.2 \mathrm{GHz}-10.6 \mathrm{GHz}$ respectively to avoid the $5.0 \mathrm{GHz}-6.0 \mathrm{GHz}$ band used by IEEE 802.11a.

Common tuning methods involve the use of varactors/PIN diodes, RF MEMs, ferroelectrics, liquid crystals and optical tuning. The use of PIN and varactor diodes has many disadvantages including high insertion loss, high power consumption and unacceptable distortion. RF MEMs offer low loss, high Q, less distortion but have very poor switching speeds. Ferroelectric materials also introduce high dielectric losses although they are readily tuned. Liquid crystals have high linearity, low tuning voltage but very slow switching time. In contrast, optically controlled silicon switches offer high power handling capability, immunity to electromagnetic interference, very low distortion and cost-effectiveness [1]. Optically controlled antennas [2], resonators [3] and couplers [4] have been demonstrated.

Although there are numerous published works available on UWB bandpass filters, there are only a few related to reconfigurable structures. Reconfigurable UWB filters have been recently proposed in [5] where four PIN diodes have been used to switch between a bandpass and bandstop response. The filter however suffers from relatively high loss as well as signal distortion due to the non-linear characteristics of the diode. A different approach is used in [6] where a switchable notch in the passband is employed to achieve reconfigurability. The notch however is relatively narrowband in nature and it is not possible to completely block the entire passband.
In this paper, we present a compact optically reconfigurable UWB filter with little loss and significantly low distortion. Moreover, the proposed filter achieves over 50\% size reduction relative to the filters in [5] and [6] and higher stopband attenuation relative to the filter in [5]. In one setting, the filter behaves as a bandpass filter with a passband between $3.1 \mathrm{GHz}$ to $5.0 \mathrm{GHz}$ while in the other mode, it behaves as a bandstop filter in the same band. Simulation and experimental results have been presented to support the discussion.

\section{OptiCALLY RECONFIGURABLE FILTER}

The layout of the proposed filter is illustrated in Fig. 1 below. The filter is composed of lines of width $1.2 \mathrm{~mm}$ and the open circuited stub leading to the gap is $2.4 \mathrm{~mm}$ wide. The $0.3 \mathrm{~mm}$ gap labelled below is overlaid with $1 \mathrm{~mm} \times 3 \mathrm{~mm}$ silicon wafer. The silicon wafer has a conductivity of 35.2 $\mathrm{mS} / \mathrm{m}$ in the dark state and a conductivity of $150.4 \mathrm{~S} / \mathrm{m}$ when optically activated [2]. Therefore, under optical illumination, the length of the open-circuited stub is effectively increased.

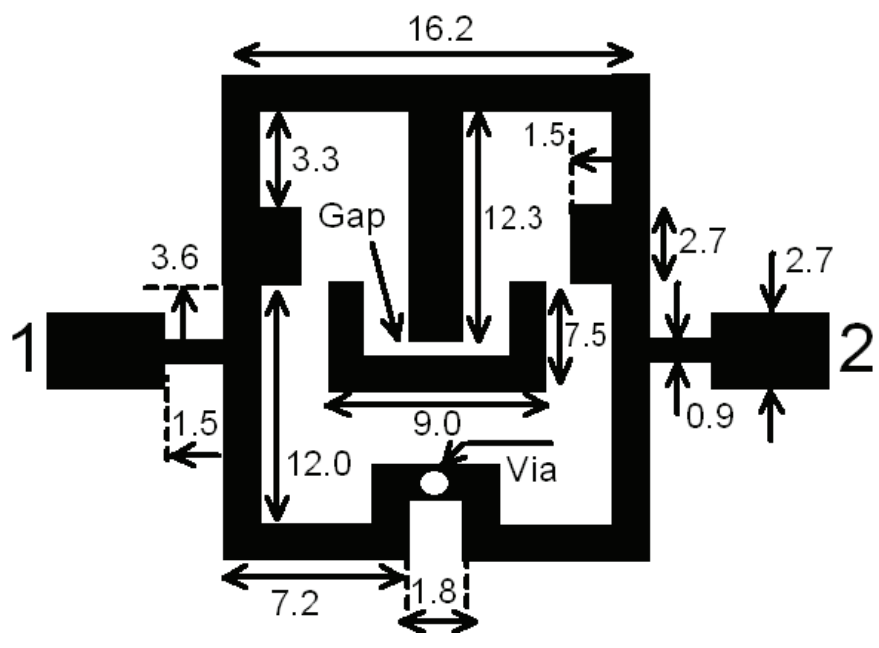

Fig. 1 Layout of the proposed UWB filter (dimensions in millimetres)

The filter in Fig. 1 is a third-order bandpass filter composed of a single $\lambda_{g} / 2$ resonator, which is placed between a pair of $\lambda_{g} / 4$ short circuited resonators. The filter is inductively 
coupled to the source and load as illustrated. Folding both short circuited resonators inwards allowed the use of a common ground via to be utilised. Furthermore, this also makes the structure compact. This filter is designed to have a $3 \mathrm{~dB}$ passband from $3.1 \mathrm{GHz}-5.0 \mathrm{GHz}$ with a mid-band frequency of $4 \mathrm{GHz}$.

The open-circuited stub placed in the symmetry plane of the filter generates a transmission zero when its electrical length is $\lambda_{g} / 4$. With the optical switch in the OFF state, the stub generates a transmission zero at $4 \mathrm{GHz}$. In this state, the structure operates as bandstop filter. When the switch is in the ON state, the length of the stub is increased and the zero appears at $2.2 \mathrm{GHz}$. The transmission zero and its first harmonic at $3 f_{0}$ improve the attenuation and selectivity of the bandpass filter in the lower and upper stopbands.

The optical switch may be modelled with an equivalent circuit given in Fig. 2. Experimental data suggests that $R_{G}$ and $R_{S}$ decrease when the optical switch is $O N$ while $C_{G}$ and $C_{S}$ increase [2]. In [1], the performance of a single optical switch was evaluated and was found to have an overall insertion-loss of around $0.68 \mathrm{~dB}$ in the $\mathrm{ON}$ state (under $200 \mathrm{~mW}$ of optical power). In the OFF state, the total series resistance increased significantly while $\mathrm{C}_{\mathrm{G}}$ and $\mathrm{C}_{\mathrm{S}}$ decreased. The EM simulations however were conducted with an open gap to model the switch in the OFF state and a bridged gap to model the switch in the ON state.

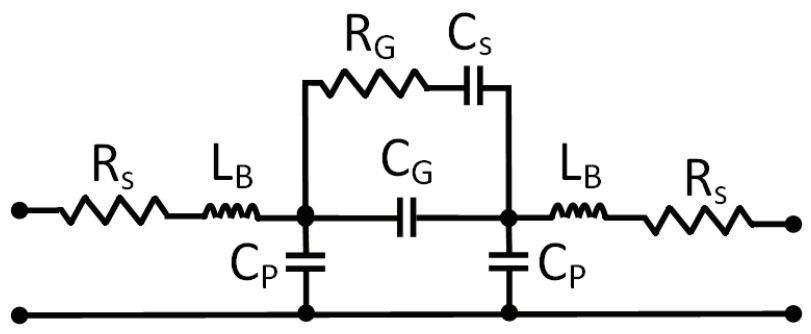

Fig. 2 Equivalent circuit of silicon switch

The filter illustrated in Fig. 1 was simulated with a fullwave EM simulator. The simulated results for the filter in both $\mathrm{ON}$ and OFF states are depicted in Fig. 3.

In order to validate the argument, the filter was fabricated on RT Duroid 5880 substrate with $\varepsilon_{\mathrm{r}}=2.2$ and $\mathrm{h}=1.575 \mathrm{~mm}$. The overall filter size was $20.4 \mathrm{~mm} \times 16.2 \mathrm{~mm}$. A $1 \mathrm{~mm} \times 3$ $\mathrm{mm}$ Silicon switch was fixed in place using a conducting silver epoxy. Two $1 \mathrm{~mm}$ diameter glass fibre optic cables were positioned over the silicon wafer as shown in Fig. 4. In the ON state, each cable delivered $200 \mathrm{~mW}$ of optical power in the $980 \mathrm{~nm}$ near infra-red range. If a smaller switch was used, activation could be performed with just one fibre optic cable. The S-parameters of the filter with the optical switch in ON and OFF states were measured with an Anritsu Lightning 37397D Vector Network Analyzer and are shown in Fig. 5. The group delay of the filter in the ON state is given in Fig. 6.

With the switch in the OFF state, the measurements show the notch at a slightly lower frequency than expected. Even in the OFF state, the silicon wafer acts as a dielectric causing $\mathrm{C}_{\mathrm{G}}$ to be larger. As a result, the length of the stub is effectively elongated slightly and therefore, the transmission zero is not quite at the desired frequency. This can be corrected by increasing the width of the gap to compensate for the increase in capacitance.

Measurements show that a rejection of better than $30 \mathrm{~dB}$ can be obtained at the centre frequency and a minimum of 10 $\mathrm{dB}$ rejection can be achieved across the desired band, which is an improvement to [5], where the minimum rejection was around $5 \mathrm{~dB}$. The measured passband insertion-loss of the bandpass filter was $0.84 \mathrm{~dB}$ and minimum passband return loss of $15 \mathrm{~dB}$ is observed. A slight frequency shift is observed between the simulated and measured results and this may be attributed to the various fabrication errors involved.

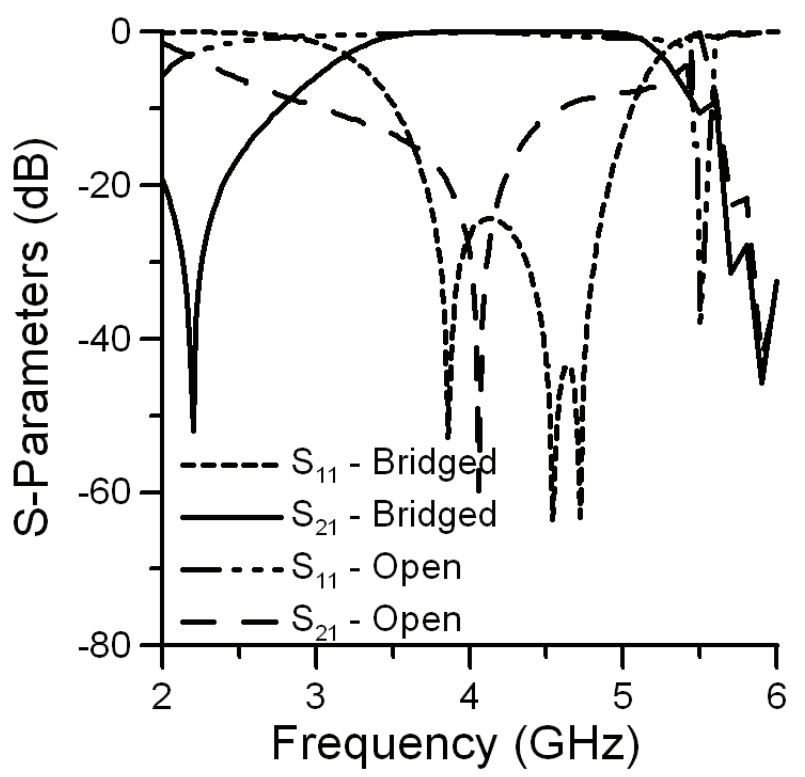

Fig. 3 Simulated response of filter with the gap in the bridged and open states

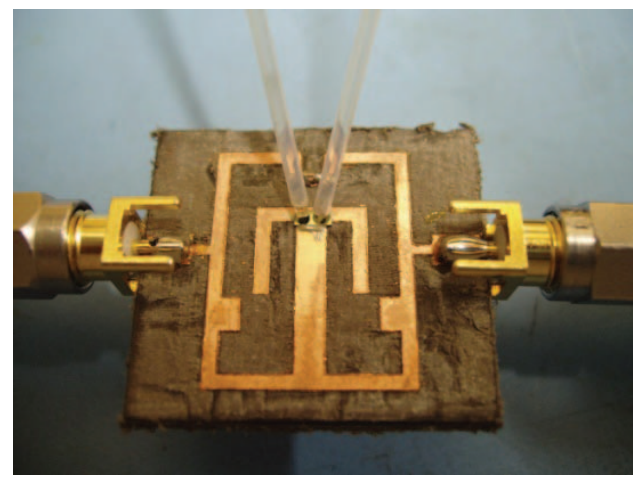

Fig. 4 Photograph of fabricated filter with optical switch 


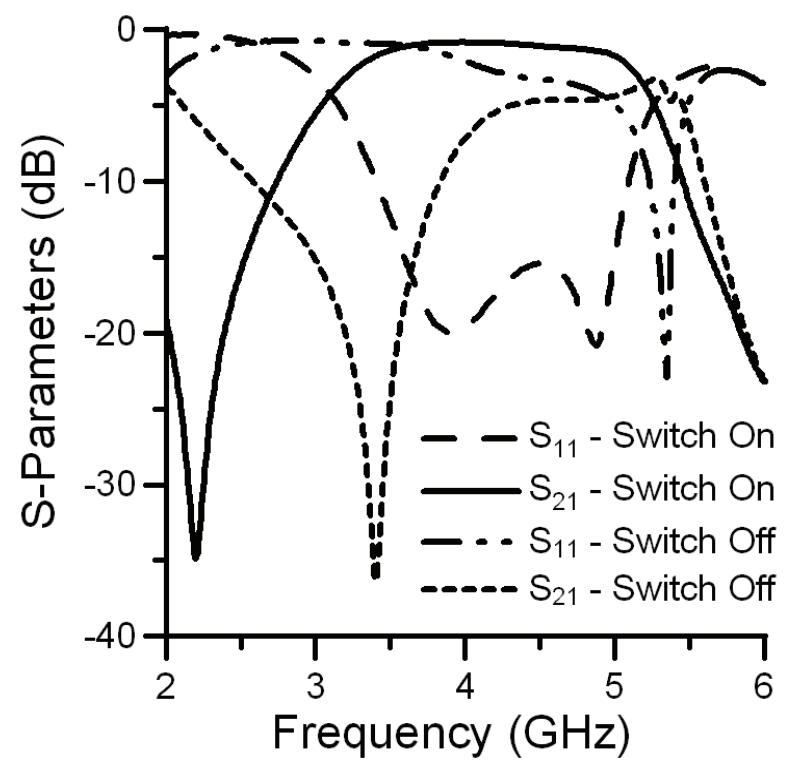

Fig. 5 Measured response of the fabricated filter with the optical switch in the $\mathrm{ON}$ and $\mathrm{OFF}$ states

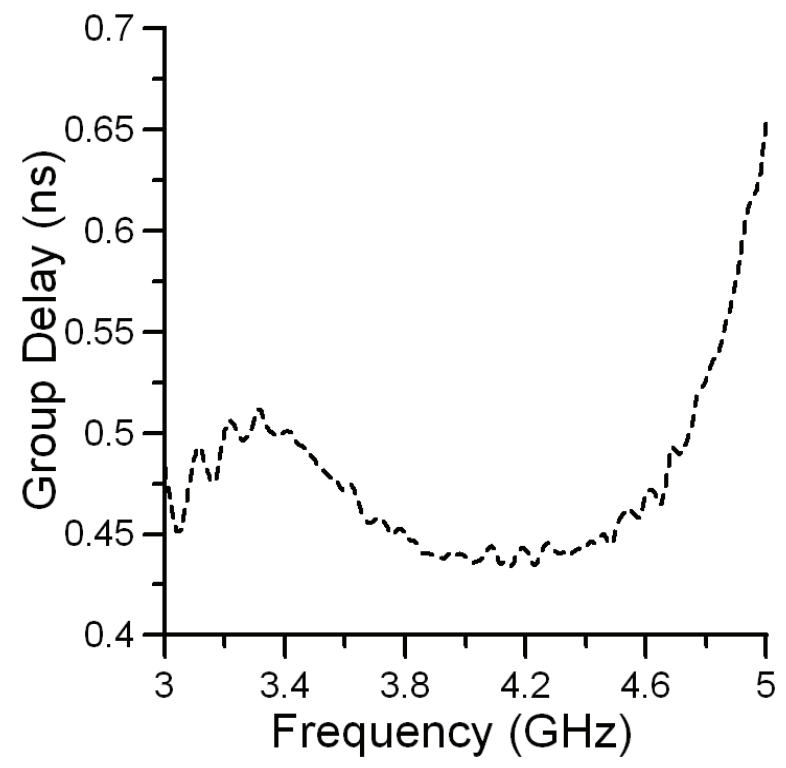

Fig. 6 Measured group delay of bandpass filter (switch ON)

\section{CONCLUSION}

An optically reconfigurable microstrip ultra-wideband filter has been presented. An optical switch was shown to reconfigure the unit as either a bandpass or a bandstop filter. Experimental results for the filter operated with an optical switch were presented. An equivalent circuit for the silicon loaded gap is presented though for simplicity, the switch was modeled as an open gap in the OFF state and a bridged gap in the ON state. The advantages of the proposed method include immunity to interference and high power handling capability.

\section{REFERENCES}

[1] D. Draskovic and D. Budimir, "Optically controlled negative refractive index transmission lines", European Conference on Antennas and Propagation, pp. 1672-1674, 2009.

[2] C.J. Panagamuwa, A. Chauraya and J.C. Vardaxoglou, "Frequency and beam reconfigurable antenna using photoconducting switches", IEEE Transactions of Antennas and Propagation, vol. 54, No. 2, pp. 449 454, 2006.

[3] G. Zouganelis and D. Budimir, "Silicon gap-loaded microstrip slittetragonal resonator under IR-radiation", Microwave and Optical Technology Letters, vol. 49, pp. 699-702,2007

[4] D. Draskovic and D. Budimir, "Optically reconfigurable dual-band compact branch-line couplers", European Conference on Antennas and Propagation, pp. 1-3, 2007.

[5] M.F. Karim, Y.X. Guo, Z.N. Chan and L.C. Ong, "Miniaturized reconfigurable and switchable filter from UWB to $2.4 \mathrm{GHz}$ WLAN using PIN diodes", IEEE MTT-S, pp. 509-512, 2009.

[6] Y.H. Chun, H. Shamman, J.S. Hong, "Switchable embedded notch structure for UWB bandpass filter", IEEE Microwave and Wireless Component Letters, vol. 18, no. 9, pp. 590 - 592, 2008. 
